\title{
Correction to: The Parasitic Nature of Social Al: Sharing Minds with the Mindless
}

\section{Henrik Skaug Sætra ${ }^{1}$}

Published online: 22 May 2020

(C) Springer Science+Business Media, LLC, part of Springer Nature 2020

\section{Correction to: Biological Trace Element Research \\ https://doi.org/10.1007/s12124-020-09523-6}

The original version of this article unfortunately contained a mistake. The first sentence under the header "Robots as Partners" should read as:

Tools, Y1ldiz (2019) says, are the by-products of solutions humans produce for social interaction.

The original article has been updated.

Publisher's Note Springer Nature remains neutral with regard to jurisdictional claims in published maps and institutional affiliations.

The online version of the original article can be found at https://doi.org/10.1007/s12124-020-09523-6

Henrik Skaug Sætra

henrik.satra@hiof.no

1 Østfold University College, Halden, Norway 